Haupt, T.C., Akinlolu, M. and Raliile, M.T., 2019. Applications of digital technologies for health and safety management in construction. In: Sandanayake, Y.G., Gunatilake, S. and Waidyasekara, A. (eds). Proceedings of the $8^{\text {th }}$ World Construction Symposium, Colombo, Sri Lanka, 8-10 November 2019, pp. 88 -97. DOI: doi.org/10.31705/WCS.2019.9. Available at: https://2019.ciobwcs.com/papers

\title{
APPLICATIONS OF DIGITAL TECHNOLOGIES FOR HEALTH AND SAFETY MANAGEMENT IN CONSTRUCTION
}

\author{
Theo C. Haupt ${ }^{1}$, Mariam Akinlolu ${ }^{2}$ and Mohlomi Terah Raliile ${ }^{3}$
}

\begin{abstract}
The construction industry has been known for many decades as a high-risk industry with low levels of innovation and reluctance to adopt change. Common causes of construction accidents are associated with human error, hazardous work activities, defective equipment and dangerous working environments. However, to provide a better and safe working environment, the industry can exploit the benefits of emerging health and safety technologies. The purpose of this study is to explore the application of various emerging technologies and how they can be used to improve construction health and safety management. The paper reviewed extensive literature from previous studies on emerging technologies and interventions for construction job site safety such as; Virtual Reality (VR), online databases, Geographic Information Systems (GIS), Building Information Modelling (BIM), Unmanned Aerial Vehicle (UAV), 4D Computer-Aided Design (4D $C A D)$, wearables, robotics, laser scanning, photogrammetry and sensor-based technologies. Furthermore, these technologies were grouped into three categories; people technologies, process technologies and environmental technologies for better analysis. Keywords such as 'construction health and safety technologies', 'digital technologies' and 'emerging technologies' were used to search online databases. This study identified emerging technologies and their application in the construction industry to improve health and safety.
\end{abstract}

Keywords: Construction; Digital; Emerging; Health and Safety; Technologies.

\section{INTRODUCTION}

Regardless of the countless efforts made by health and safety authorities and government agencies to improve health and safety standards on construction sites, worker's injuries and fatalities continue to occur at alarming rates (Li, 2015). Defective equipment, human behaviour, dangerous work areas and unsafe working conditions are cited as common causes of construction site injuries and fatalities (Li, 2015; Hinze and Teizer, 2011). In light of these, various types of technologies and interventions have been developed to prevent worker's injuries, accidents and enhance construction job site health and safety (Welch et al., 2015; Dodge Data and Analytics, 2017; Zhou, Whyte and Sacks, 2011).

\footnotetext{
${ }^{1}$ Construction Management \& Quantity Surveying, Mangosuthu University of Technology and School of Engineering, University of Kwa-Zulu Natal, South Africa, theo.haupt@mut.ac.za or Haupt@ukzn.ac.za

${ }^{2}$ School of Engineering, University of Kwa-Zulu Natal, South Africa, akinlolumariam@gmail.com

${ }^{3}$ School of Engineering, University of Kwa-Zulu Natal, South Africa, mohlomiraliile@gmail.com
} 
There has been a rapid increase in the use of emerging technological innovations to enhance health and safety on job sites in recent years. Several studies have concentrated on the application of digital technologies such as Virtual Reality (VR), online databases, Geographic Information Systems (GIS), Building Information Modelling (BIM), Unmanned Aerial Vehicle (UAV), 4D Computer-Aided Design (4D CAD), wearable robotics, laser scanning, photogrammetry and sensor-based technologies for accident prevention and onsite safety (Dodge Data and Analytics, 2017; Teizer, 2016; Bock, Linner and Ikeda, 2012; Li and Ng, 2017; Zhou et al., 2011).

Utilising emerging technologies provides significant prospects to improve construction health and safety management and ensure efficiency in construction work (Teizer, 2016); (Zhou et al., 2013). This paper aims to explore the various emerging technologies implemented for construction health and safety management. A comprehensive review of previous studies is conducted to establish the emerging technology adoptions as reported in numerous studies. The study categorizes these technologies into groups; people technologies, process technologies and environmental technologies. The main characteristics of these technologies are discussed in detail in the study.

\section{DIGITAL TECHNOLOGIES AND TRENDS IN CONSTRUCTION H\&S MANAGEMENT}

Digital technologies in construction have been in existence since hard hats and protective glasses ( $\mathrm{Li}$ and $\mathrm{Ng}, 2017$ ). In recent times, the combination of big data, technological genius and construction has improved the health and safety of workers on construction sites (ibid). With the development of new technologies, the use of technology continues to draw attention (Zhou et al., 2013). A variety of tools have been developed to assist contractors to achieve health and safety on their construction projects. Numerous studies have identified the use of digital technologies such as BIM, VR and AR, drones, GIS, automation and robotics, unmanned machinery, sensing and warning technologies, 4D CAD as effective technologies for an accident, prevention and safe project delivery (Zhou et al., 2011).

\subsection{PeOPle TECHNOLOGIES}

People technologies are digital tools applied to ensure the health and safety of workers by what they wear. Teizer et al. (2007) revealed that through the application of emerging technologies in health and safety, construction workers could be provided with layers of protection. Previous research efforts have explored the interaction and collision between heavy equipment and workers on construction sites (Li and Leung, 2017). The awareness of workers and visibility of equipment operators decreases because of the repetitive nature of construction activities (Teizer et al., 2007). Numerous studies have identified automation and robotics as effective technologies with good prospects to enhance proactive workers' safety on construction sites (Zhou et al., 2011). Automated platforms have been developed for the construction of high-rise structures (Li and Leung, 2017). This building system requires less labour and aims to reduce and eliminate injuries caused by over-exertion (Teizer, 2015). Workers competences and limitations are accommodated by transforming the work environment to provide an accident- free zone (ibid). 


\subsubsection{Robotics and Automation}

Adopting robotic systems is a current trend for accelerating and automating construction tasks (Chu et al., 2013; Bock et al., 2012). Controlled by computers on-site and dependent on advanced detection and control, robots are employed in the autonomous installation and gathering of heavy construction materials, which usually require enormous labor, and to construct structures such as skyscraper towers (Niu et al., 2017; Jung et al., 2013; Li and Leung, 2017). One of the pioneer automation systems was a masonry robot that used seam adhesive to glue bricks and could lay brick walls up to 8m long. Yu (2009) discovered an automated machine called "Blockbot" which is utilised on-site to erect straight bonded brick walls accurately.

Navon and Kolton (2006) developed a model for automation in monitoring and managing fall hazards in scheduled building construction projects. This model determines high-risk areas in construction activities and gives a graphical presentation on the project's drawings (Azmy and Zain, 2016). Balaguer et al. (2002) proposed the use of ROMA climbing robots for inspection of steel-based infrastructures in construction. This robotic system is a self-supporting locomotion system that conducts inspections in 3D complex environments and operates similarly to a caterpillar.

\subsubsection{Wearable Technology and Smart PPE}

Wearables are clothing or accessories that have technologies incorporated into them, such as hats or watches. Physical processes and gestures such as waving heartbeat are captured and used to control a physical process or external event (Zhang et al., 2017). Wearable technologies have been designed to eliminate falls, electrocutions, and caught-in-between accidents. The smart hat or helmet is a warning technology equipped with special lenses, 4D augmented reality and a transparent visor. DAQRI developed a hard hat with a sensor bar for alignment and tracking activities. The hat detects potential site hazards and provides instructions and warnings (Teizer et al., 2010). Similarly, smart PPE's such as safety vests with sensors and GPS incorporated in them have been designed to protect construction workers during fall accidents (Zhou et al., 2013).

\subsection{Process TeChNOLOGIES}

These are digital tools applied to ensure safe construction activities on job sites. At the process level, considerable efforts have been made to promote and ensure health and safety (Zhou et al., 2011). Online databases are generally used in combination with various research tools to assess stakeholder competence and enable the communication of safety information within companies (Yu, 2009). The 3D and 4D CAD have been applied in construction projects to identify potential design risks and analyse on-site dynamics to enable safe project delivery (Ku and Mills, 2010). Hu et al. (2008); Bansal (2011); Merivirta et al., (2011) revealed that combining BIM and 4D CAD was adopted for the assessment and planning of construction health and safety as well as management of safety information.

\subsubsection{Online Databases}

Online systems have been used to improve several aspects of construction health and safety such as safety training and education, risk identification, safety monitoring and evaluation and safety inspections (Dodge Data and Analytics, 2017). Online databases can be utilized to detect potential site hazards and evaluate competence (Zhou et al., 
2012). Yu (2009) designed a prototype web tool to assist in the evaluation of potential designers, contractors and coordinators. The online system applies Artificial Intelligence (AI) during the evaluation process to support decision making through risk identification and assessment, and information capture and analysis (Zhou et al., 2012).

The Construction Safety and Health System (CSHM) is a web-safety monitoring system that detects potential site risks and gives warning signals for activities that need immediate interventions (Cheung et al., 2004). The system enhances quick data search, uploads, collection and documentation through remote internet access (Azmy and Zain, 2016). Health and safety indicators from diverse projects are understood, and valuable information is obtained to improve construction health and safety management. Project performance is monitored over a specified period by analyzing scores assigned to specific parameters (Yu, 2009). Azmy and Zain (2016) identified the development of a real-time communication system for monitoring construction safety on diverse projects. A centralized database is used to store transmitted data and is analyzed by site managers to inform decisions on construction sites (ibid). This system is an alternative platform for sourcing construction health and safety reports and statistics.

\subsubsection{Internet of Things (IoT)}

IoT has recently become an enormous innovation and trend in the history of technological advancement (Cheung et al., 2004). The network comprises the interaction of embedded tools and devices accessed and connected to the internet through wired and wireless networks. IoT monitoring technologies are adapted to monitor site activities that require constant close attention (Dodge Data and Analytics, 2017). Applications are designed to enhance decision-making processes by transmitting real-time responses among workers (Jing et al., 2014). For smart construction health and safety information is collected with the use of sensors and gateways, clouds are then used to wirelessly store, analyse and review the data collected (Hopah and Vayvay, 2018).

Riaz et al. (2006) developed a proactive communication system to reduce human and equipment collisions on construction sites. A combination of GPS, smart sensors and wireless networks are applied to track site workers and equipment and inform operatives about impending site hazards. The system generates reports on dangerous activities and near-miss accidents (Azmy and Zain, 2016). Wireless Application Protocol (WAP) and Multimedia Messaging Service (MMS) have been used to manage safety-related issues on site by sending notifications to site workers who then swiftly communicate via text message when corrective action is taken (Bowden et al., 2006).

\subsubsection{Building Information Modelling (BIM)}

Implementing BIM enables visual assessment of construction site and identify potential hazards (Azhar et al., 2012; Watson, 2010). A result of incorporating BIM in construction activities is developing health and safety-training videos for workers (ibid). Using the BIM model to conduct visual health and safety training enables site workers to develop a better understanding of the actual site conditions (Watson, 2010). Construction workers are provided with sufficient time and information for safety planning and management before executing construction activities. With the use of sensors for data collection, the BIM can adequately reduce the likelihood of site accidents by checking the procedure of data acquisition (Druley et al., 2016); (Ganah and John, 2015). In adopting the BIM technology, health and safety issues are considered during construction planning, with provision of a clearer layout of site and safety plans giving strategies to manage site 
information as well as enhancing health and safety communication among project partners through time-controlled simulation (Azhar et al., 2012; Ku and Mills, 2010).

$\mathrm{Ku}$ and Mills (2010) assessed the capability of BIM as a safety tool. The study indicated that BIM promotes teamwork between project stakeholders using automated specifications and guidelines such as codes and regulatory information. By using a theoretical framework, the effectiveness of BIM for safety was evaluated. Given the concept introduced by $\mathrm{Ku}$ and Mills (2010), Qi et al. (2011) developed a safety checking system for construction activities. This system automatically checks the BIM model for fall dangers.

\subsubsection{D and 4D CAD}

Health and Safety experts use 3D CAD for safety planning, accident investigation and facility maintenance safety (Rajendran and Clarke, 2011). Additionally, 4D CAD is utilized to simulate safety processes to display safety components and high-risk areas during the project's life cycle (Azhar et al., 2012). Rwamamara et al. (2010) concluded that the use of 3D and 4D technologies in the early stages of construction projects allows the project team to identify potential risks. Identifying risks at an early stage minimizes cost over-runs that occur because of design changes (Azmy and Zain, 2016).

In one case study, Mallasi (2006) applied 4D visualisation technology to detect and analyse workplace time-space congestion. Critical Space-Time Analysis (CSA) was used to analyse competition between various construction activities sharing similar execution space (Zhou et al., 2012). Benjaoaran and Bhokha (2009) developed a rule-based construction safety management system using the 4D CAD visualisation model. The system focused on automatically identifying fall from heights hazards since fall accidents and injuries occurred more frequently compared to other accidents on construction sites (Azmy and Zain, 2016). Data relating to activities and building's component, placement, arrangement, materials, equipment are inputted and analysed to detect any height-related hazards (Zhou et al., 2012). The system proposes appropriate safety requirements and measures.

\subsection{ENVIRONMENT TECHNOLOGIES}

Environment technologies are tools adopted to ensure the health and safety of the construction environment. GIS and Global Position Systems (GPS) have been combined to understand issues of construction safety by taking into consideration design information, project structure and impact of construction activities on the external environment (Zhou et al., 2011); (Bansal, 2011). Similarly, integration of the GPS and RFID wireless sensor networks was developed to provide real-time information and monitor site workers, equipment, alert employees, and contractors about impending danger (Riaz et al., 2006; Teizer et al., 2015).

\subsubsection{Smart Sensors and Wireless Networks}

The application of sensors plays a significant role in implementing construction health and safety through real-time monitoring of buildings or building components (Zhang et al., 2017). Sensor-based technologies have been applied to prevent accidents and prevent worker - equipment collisions by monitoring the entire environment on construction sites. Ahsan et al. (2007) highlighted the sensor-based location, vision-based sensing and 
wireless sensor networks as the various types of sensor technologies applied to construction safety management.

Wireless sensor networks have been found to enhance and facilitate information flow among design teams on construction sites (Ward et al., 2004; Brilakis, 2007). Complexities of the construction environment make the circulation of a network a difficult task; however, wireless networks present solutions to this problem (Ahsan et al., 2007). Brilakis (2006) found that visual inspection methods employed to monitor bridge construction projects do not provide detailed and reliable information. New technologies such as wireless radio transmitters have been developed to monitor and inspect bridge construction projects (ibid). GSM, Wireless Local Area Network (WLAN), Terrestrial Trunked Radio (TETRA) are the various types of wireless technologies that have been tested on construction site operations (Zhang et al., 2017). Ahsan et al. (2007) identified a wireless network known as Wi-MESH to provide remote backend access and connection to the internet on construction sites where telephone access is restricted (Brilakis, 2007).

\subsubsection{Virtual Reality (VR)}

Virtual Reality is an artificial, computer-generated experience of a real-life situation or environment (Bouchlaghem et al., 2005). It generates realistic imagery and hearing, making the user feel like they are experiencing the simulated reality first-hand. In construction, virtual reality has been used by the health and safety teams to review safety tie-off points and coordinating major crane picks over occupied facilities that cannot be disrupted. This allows for effective means to visualize and communicate the impact of major construction activities in existing facilities that could be overlooked when viewing through traditional techniques (Zhang et al., 2017). Virtual Reality also creates a genuine health and safety work experience viable for construction health and safety training ( $\mathrm{Li}$ and Leung, 2017). These benefits health and safety training as exercises on health and safety can be carried out in the absence of a qualified safety administer by merely simulating the training environment on a personal computer (ibid).

Zhou et al. (2011) argued that traditional paper-based handouts, videotapes or slide shows hardly present electrical hazards vividly to the trainees and furthermore do not provide sufficient opportunities for trainees to interact in activities. This form of participatory training brings a real-life situation into the training in an "it can happen to you" scenario and allows the trainee to relate these regulations and conditions to real-life situations of with life and death significance (ibid).

\subsubsection{Augmented Reality (AR)}

As opposed to virtual reality which uses computer-generated imagery to simulate reallife scenarios; augmented reality enhances reality using technology (Bouchlaghem et al., 2005). However, the enhancements can be distinguished where such interactions are developed into applications and mobile devices (Patrucco et al., 2010). Augmented Reality projects 3D imagery on a person's physical surroundings as they walk through construction sites with mobile devices or special helmets and using GPS and cameras to present real-time data geospatially giving updated user feedback (Bouchlaghem et al., 2005). Health and safety training may be conducted with this technology by enabling workers to wear augmented reality headsets to give virtual drills, instructions and safety scenarios at low training costs and downtimes (ibid). 


\subsubsection{Radio Frequency Identification (RFID)}

Radio Frequency Identification (RFID) uses radiofrequency waves to transmit data, retrieve data and store data to identify the status of workers and objects (Yin et al., 2013). RFID systems are composed of an RFID tag and RFID reader, with RFID tags consisting of a small microchip and antenna. Data are stored in the tag, generally as a unique serial number. RFID tags can either be active (using battery) or passive (no battery) or have a read range of 10 to 100 meter (ibid).

In construction health and safety applications, RFID technology has been used to demonstrate real-time data gathering (Li and Leung, 2017). RFID tags have been used in simulated construction environment to track the movement of workers, equipment and materials and the resulting tag data examined to determine if a near-miss accident has occurred (Zhou et al., 2013). This information can further be used to prevent future occurrences (ibid). Chae (2009) designed a Collision Accident Prevention Device (CAPS) that uses RFID (Radio Frequency Identification) technology to estimate the size of the working area. The device supports accident prevention involving vehicles, heavy equipment and workers using data from the working area of each object. CAPS estimates and calculates the positional relation of heavy equipment and workers and once determined that a worker is in the restricted area of heavy equipment, a warning message is sent to the worker and concerned parties (ibid).

\section{METHODOLOGY}

The study adopts a traditional literature review approach to explore the different existing emerging technologies used in construction health and safety management. Relevant research and studies on advanced technology implementation and construction health and safety were primarily obtained from multiple research databases and online-computerized search engines including Elsevier (Science Direct), Taylor and Francis, Emerald Insight, Research Gate and other internet sources. A systematic and extensive database search was conducted using initial descriptors such as technology, health and safety and construction site and technologies categorised according to their functionalities; people technologies, process technologies and environmental technologies. Other keywords related to advanced and emerging technologies such as 'sensor', 'wireless network', 'robotics', 'remote sensing' and 'laser scan' were identified. Articles reviewed and cited in this study includes articles published in reputable scholarly journals and reports. Significant papers and articles relating to the study were selected and collated to construct a database.

\section{DISCUSSION AND RECOMMENDATIONS}

In this study, it was found that standard health and safety practices and policies combined with the implementation of digital health and safety tools and techniques could assist site managers, supervisors and coordinators ensure the efficiency of their construction projects. Accidents can be reduced tremendously with the use of people technologies to ensure workers safety by what they wear and how they interact with their work environment. Furthermore, process technologies may be used to eliminate hazards during the design stage and with the assistance of environmental technologies used to give updated feedback on the work environment. The industry must take advantage of breakthroughs in technological advances such as the Internet of Things (IoT). With this 
technology, the interaction of all mechanical devices, digital devices and computers combine the digital and physical worlds. Advanced Artificial Intelligence (AI) systems can be used to improve site health and safety, assist in information sharing and instantly report dangerous activities. Therefore, investing in emerging technologies enhances health and safety performance on construction sites.

\section{CONCLUSIONS}

This paper has provided a comprehensive and traditional review of previous literature on technology adoptions and implementations in construction health and safety management. The technologies were grouped into three categories, people technologies, process technologies and environmental technologies. The importance of construction workers' health and safety continues to grow in the construction industry. It is discovered that the application of digital technologies can effectively promote construction health and safety management. Numerous studies have been conducted on the application of various types of technologies in aspects of construction health and safety such as site safety education and training, safety communication and information and site monitoring and control. The adoption of various safety technologies like 3D and 4D CAD, RFID, augmented reality, virtual reality, Building Information Modelling, smart sensor and wireless technology, online databases, robotics and automation have significantly increased the effectiveness of health and safety management on construction sites. Applying advanced technologies in construction health and safety may provide a practical means for safety personnel and practitioners to track and monitor interactions on construction sites.

\section{ACKNOWLEDGEMENT}

The authors much acknowledge the support of the National Research Fund (NRF).

\section{REFERENCES}

Ahsan, S., El-Hamalawi, A., Bouchlaghem, D. and Ahmad, S. 2007. Mobile Technologies for Improved Collaboration on Construction Sites, Architectural Engineering and Design Management, 3, pp.257272.

Azhar, S., Bahringer, A., Khalfan, M., Sattineni, A. and Maqsood,T. 2012. BIM for Facilitating Construction Safety Planning and Management at Jobsite, Proceeding of the CIB W099 International Conference on Modelling and Building Health and Safety, pp.82-92.

Azmy, N. and Zain, A. 2016. The Applications of Technology in Enhancing Safety and Health Aspects on Malaysian Construction Projects, ARPN Journal of Engineering and Applied Sciences, 11, pp.72097213.

Balaguer, C. and Abderrahim, M. 2008. Trends in Robotics and Automation in Construction, Robotics and Automation in Construction, Intechopen.

Bansal, V.K. 2011. Application of geographic information systems in construction safety planning," International Journal of Project Management, 29, pp.66-77.

Benjaoran, V. and Bhokha, S. 2009. Enhancing visualization of 4D CAD model compared to conventional methods. Engineering, Construction and Architectural Management, 16(4), pp.392-408.

Bock, T., Linner, T. and Ikeda, W. 2012. Exoskeleton and Humanoid Robotic Technology in Construction and Built Environment, The Future of Humanoid Robots - Research and Applications, Intechopen.

Bouchlaghem, D., Shang,H. and Whyte,J., Ganah,A. 2005. Visualisation in architecture, engineering and construction (AEC), Automation in Construction, 14 (3), pp.287-295.

Bowden, S., Dorr, A., Thorpe, A. and Anumba, C. 2006. Mobile ICT support for construction process improvement, Automation in Construction, 15(5), pp.664-676. 
Brilakis, I. 2006. Remote Wireless Communications for Construction Management: A Case Study, Joint International Conference on Computing and Decision Making in Civil and Building Engineering, pp.135 - 144.

Brilakis, I., 2007. Long-distance wireless networking for site - office data communications, ITCon, 12, pp.151-164.

Chae, S. 2009. Development of Warning System for Preventing Collision Accident on Construction Site, 26th International Symposium on Automation and Robotics in Construction.

Cheung, S.O, Cheung, K.K.W and Seun, H.C.H. 2004. CSHM: Web-based safety and health monitoring system for construction management, Journal of Safety Research, 35(2), pp.159-170.

Chu, B., Jung, K., Lim, M.T. and Hong, D., 2013. Robot-based construction automation: An application to steel beam assembly (Part I). Automation in Construction, 32, pp.46-61.

Dodge Data and Analytics 2017. Safety Management in the Construction Industry, Smart Market Report, Bedford, MA.

Druley, K., Musick, T. and Trotto, S., 2016. Researcher explores how to make temporary structures on the construction site safer. Safety \& Heath, 193(3), p.35.

Ganah, A. and John, G.A. 2015. Integrating building information modelling and health and safety for onsite construction, Safety and Health at Work, 6, pp.39-45.

Hinze, J. and Teizer, J. 2011. Visibility-related fatalities related to construction equipment, Safety Science, 49, pp.709-718.

Hopah, E. and Vayvay, O. 2018. Internet of Things (IoT) and its Challenges for Usability in Developing Countries, International Journal of Innovation Engineering and Science Research, 2(1), pp.1-9.

Hu, Z., Zhang, J. and Lu, X. 2010. Development of a sub building information model for 4D structural safety analysis during construction, Proceedings of the International Conference on Computing in Civil and Building Engineering (ICCCBE 2010), Nottingham, UK.

Jing, Q., Vasilakos, A. Wan, J., Lu, J. and Qiu, D. 2014. Security of the Internet of Things: Perspectives and challenges, Wireless Networks, 20, pp.2481-2501

Jung, K., Chu, B. and Hong. 2013. Robot-based construction automation: An application to steel beam assembly (part ii), Automation in Construction, 32, pp.62-79.

$\mathrm{Ku}, \mathrm{K}$. and Mills, T. 2010. Research needs for Building Information Modelling for Construction Safety, International Proceedings of Associated Schools of Construction 45 th Annual Conference, Boston, MA.

Li, R.Y. 2015. Generation x and y's demand for homeownership in Hong Kong, Pacific Rim Real Estate Journal, 21, pp.15-36.

Li, R.Y.M., and Ng, P.L. 2017. Wearable robotics and construction workers safety and health. In: 8th International Conference on Applied Human Factors and Ergonomics, Los Angeles.

Li, R. Y. and Leung, T. 2017. Leading safety indicators and automated tools in the construction industry, 34th International Symposium on Automation and Robotics in Construction.

Mallasi, Z. 2006. Dynamic quantification and analysis of the construction workspace congestion utilizing 4D visualization, Automation in Construction, 15, pp.640-655.

Merivirta, M., Ma“kela”, T., Kiviniemi, M., Ka"hko"nen, K., Sulankivi, K. and Koppinen, T. 2011. Exploitation of BIM based information displays for construction site safety communication, in Proceedings of CIB W99 Conference 2011: Washington, USA, 24-26 August, pp.402-415.

Navon, R. and Kolton, O., 2006. Model for automated monitoring of fall hazards in building construction. Journal of Construction Engineering and Management, 132(7), pp.733-740.

Niu, Y., Lu, W. and Liu, D. 2017. The application scenarios of smart construction objects (SCOs) in Construction, Proceedings of the 20th International Symposium on Advancement of Construction Management and Real Estate, pp.969-980.

Patrucco, M., Bursano, D., Cigna, C. and Fissore, F. 2010. Computer image generation for job simulation: an effective approach to occupational risk analysis, Safety Science ,48, pp.508-516.

Qi, J., Issa, R., Hinze, J. and Olbina, S. 2011. Integration of safety in design through the use of building information modeling. International Conference on Computing in Civil Engineering, Miami, U.S., pp.698-705. 
Rajendran, S. and Clarke, B. 2011. Building Information Modeling: Safety benefits and opportunities, Professional Safety, pp.44-51.

Riaz, Z, Edward, D. and Thorpe, A. 2006. SightSafety: A hybrid information and communication technology system for reducing vehicle/pedestrian collisions, Automation in Construction, 15, pp.719728.

Rwamamara, R., Norberg, H., Olofsson, T. and Lagerqvist, O. 2010. Using Visualization Technologies for Design and Planning of a Healthy Construction Workplace, Construction Innovation, 10, 248-266.

Teizer, J. 2015. Wearable, Wireless Identification Sensing Platform: Self- Monitoring Alert and Reporting Technology for Hazard Avoidance and Training (SmartHat), Journal of Information Technology in Construction, 20, pp.295-312.

Teizer, J., Caldas, C.H., and Haas, C.T. 2007. Real-Time Three-Dimensional Occupancy Grid Modeling for the Detection and Tracking of Construction Resources. ASCE Journal of Construction Engineering and Management, 133, pp.880-888.

Teizer, J., Allread, B.S., Fullerton, C.E. and Hinze, J. 2010. Autonomous pro-active real-time construction worker and equipment operator proximity safety alert system. Automation in Construction, 19 (5), pp.630-640.

Teizer, J. 2016. Right-time vs real-time pro-active construction safety and health system architecture, Construction Innovation, 16 (3), pp.253-280

Ward, M., Thorpe, T., Price, A. and Wren, C. 2004. Implementation and control of wireless data collection on construction sites, Journal of Information Technology in Construction, 9, pp.299-311.

Watson, A. 2010) "BIM - driver for change, Proceedings of the International Conference on Computing in Civil and Building Engineering, ICCBE 2010, Nottingham.

Welch, L., Russell, D., Weinstock. D. and Betit, E. 2015. Best Practices for Health and Safety Technology Transfer in Construction, American Journal of Industrial Medicine, 58, pp.849-857.

Yin, S.Y.L., Tserng, H.P., Wang, J.C.and Tsai, S.C. 2009. Developing a precast production management system using RFID technology, Automation in Construction, 18, pp.677-691.

Yu H. 2009. A knowledge-based system for construction health and safety competence assessment. University of Wolverhampton. United Kingdom.

Zhang, M., Cao, T. and Zhao, X. 2017. Applying Sensor-Based Technology to Improve Construction Safety Management, Sensors, 17, pp.1-24.

Zhou, W., Whyte, J. and Sacks, R. 2012. Construction safety and digital design: A review, Automation in Construction, 22, pp.102-111.

Zhou, N., Ding, L.Y and Chen, L.Y. 2011. Application of 4D visualization technology for safety management in metro construction, Automation in Construction, 34, pp.25-36.

Zhou, Z., Irizarry, J. and Li, Q. 2013. Applying advanced technology to improve safety management in the construction industry: a literature review, Construction Management and Economics, 31, pp.606-622. 